\title{
Accuracy of implant transfer using closed tray technique with different viscosities of polyvinyl siloxane
}

\author{
Beyabanaki $\mathrm{E}^{1}$, Siadat $\mathrm{H}^{1}$, Fathi $\mathrm{B}^{2}$, Alikhasi $\mathrm{M}^{3 *}$ and Ghodsi $\mathrm{S}^{4}$ \\ ${ }^{1}$ Dental Implant Research Center, Prosthodontic Department, Tehran University of Medical Science, Tehran, Iran \\ ${ }^{2}$ Endodontic Department, Tehran University of Medical Science, Tehran, Iran \\ ${ }^{3}$ Dental Research Center, Prosthodontic Department, Tehran University of Medical Science, Tehran, Iran \\ ${ }^{4}$ Safoora Ghodsi, Assistant Professor, Department of Prosthodontics, Tehran University of Medical Sciences, Tehran, Iran
}

\begin{abstract}
Statements of problem: For simultaneous making impression of implants and teeth, both dimensional and surface detail accuracyshould be considered. The purpose of this in vitro study was to evaluate and compare the accuracy of implant transfer and surface detail reproduction with different techniques and viscosities of polyvinyl siloxane (PVS) impression material.

Method of study: A model with two implants (Implantium, Dentium) and three lines of $0.25,0.50$ and 0.75 mm in width was fabricated. Forty impressions with one-step and two-step putty/wash PVS using closed custom and stock trays and ten impressions with regular viscosity PVS using closed custom-trays were made. Impressions were poured and the positional accuracy of the implant replica heads in $\mathrm{x}^{-}, \mathrm{y}^{-}(\Delta \mathrm{r})$ and angular displacement $(\Delta \theta)$ were evaluated using a coordinate measuring machine. Also, accurate reproduction of the lines was evaluated by a video measuring machine. These measurements were compared with the measurements calculated on the reference model that served as control, and the data were analyzed with two-way analysis of variance at $\alpha=0.05$.
\end{abstract}

Results: There was more angular displacement in one-step custom-tray group compared to one-step stock-tray group $(P<0.001)$. However, less vertical displacement using custom tray with two-step technique $(P=0.003)$. Also, one-step technique showed less vertical and angular inaccuracies as compared to two-step one, using stock tray $(P<0.05)$. Regular-viscosity group showed more linear displacement compared to all other groups $(P<.001)$. The detail reproduction had no statistically significant differences $(P>0.05)$.

Conclusions: In this study both stock tray and custom tray were acceptable and the viscosity of impression material made no significant difference in surface detail reproduction.

\section{Introduction}

Dental implants have introduced a wide range of treatment options for completely and partially edentulous patients. There may be clinical situations that indicate making a single impression of implants and prepared teeth simultaneously while treating partially edentulous patients with dental implants and conventional fixed prostheses. This situation would encounter the clinician with a concern about using an appropriate impression material and technique which can guarantee accurate transferring of intra-oral relationship of implants and surface details of teeth to the definitive casts to help fabricating well-fitting cast restorations $[1,2]$.

Cannistraci et al. [3] described an impression technique for arches requiring both implant and natural tooth restorations. They first made an impression of teeth using two-step putty wash technique with polyvinyl siloxane (PVS) impression material and a custom tray, followed by an over impression after securing transfer copings, using regular viscosity PVS.

Since the passive fit of the superstructure on the abutments is essential for long term success of implant-supported prosthesis [4], making accurate impressions as the first step for achieving this fitness is mandatory [5]. Misfit of the implants could results in many complications including screw loosening, fixture fracture, bone loss and occlusal discrepancy [6-8]. Comparing of different implant impression techniques has been recorded in the literature [1,9-14] and both direct (open tray) and indirect (closed tray) techniques are commonly used [1].

Making an accurate impression is a function of several factors, including impression material, impression technique and tray selection [15-27]. Among impression materials, PVS is one of the best choices in fixed and implant dentistry because of its superior recovery from deformation, superior physical properties such as resistance against stresses during removal without tearing, dimensional changes and precise reproduction of details [28-30]. Impression of prepared teeth must not only be dimensionally accurate but also must reproduce the surface details of prepared teeth to help fulfill fitness and success of cast restorations [2]. Surface detail reproduction of elastic impression materials such as PVS impression materials has been evaluated using criteria of ADA specification No. 19 [31,32].

PVS impression materials are available in a wide range of viscosities

Correspondence to: Marzieh Alikhasi, Dental Research Center, Department of Prosthodontics, School of Dentistry, Tehran University of Medical Sciences, North Amirabad St., Tehran, Iran, E-mail: m_alikhasi@yahoo.com, malikhasi@razi.tums.ac.ir

Key words: impression technique, impression material, detail reproduction

Received: March 25, 2015; Accepted: April 22, 2015; Published: April 25, 2015 
(light, medium, heavy and very heavy or putty material). Impression making of teeth and implants requires certain viscosities in the selected trays. The optimal thickness of elastomeric impression materials in trays is 2 to $4 \mathrm{~mm}$ and it must be distributed uniformly [33]. Use of a variety of viscosities in one-step and two-step techniques for teeth or implant impression making has been the subject of a few investigations [34-37]. The two-step putty/wash technique has been shown to be more accurate than the one-step technique [34-36]. Wenz et al. [37] reported that the one-step technique was more accurate than two-step technique for making impression of implants with an internal hexagon connection.

The type of tray used for impression making can also affect the results [38]. Generally it is claimed that rigid custom trays are more accurate than plastic stock trays for implant and tooth impression making, because of their rigidity and providing consistent thickness for elastomeric materials [38-40]. However, some authors have reported that accurate casts can be made with either stock trays or custom trays and differences between custom and stock trays may not be clinically significant for tooth impression making $[40,41]$.

Therefore, to have accurate impressions of implants and teeth, both dimensional accuracy and surface detail reproduction should be considered. However, limited studies have evaluated this issue. The purpose of this in vitro study was to evaluate and compare the accuracy of different impression techniques and viscosities of PVS in closed stock and custom trays for transfer of implants and surface detail reproduction. The null hypothesis was that there is no difference between the accuracy of casts made of different impression techniques and viscosities of PVS in stock and custom trays.

\section{Materials and methods}

In this in vitro study a maxillary metal reference model was fabricated (Figure 1) with two parallel holes, $3.8 \mathrm{~mm}$ in diameter and $10 \mathrm{~mm}$ in length according to the size of implants, in the site of left first and second molars. Auto-polymerizing acrylic resin (Technovits 4000, HeraeusKulzer GmbH \& Co.) was used for securing the implants

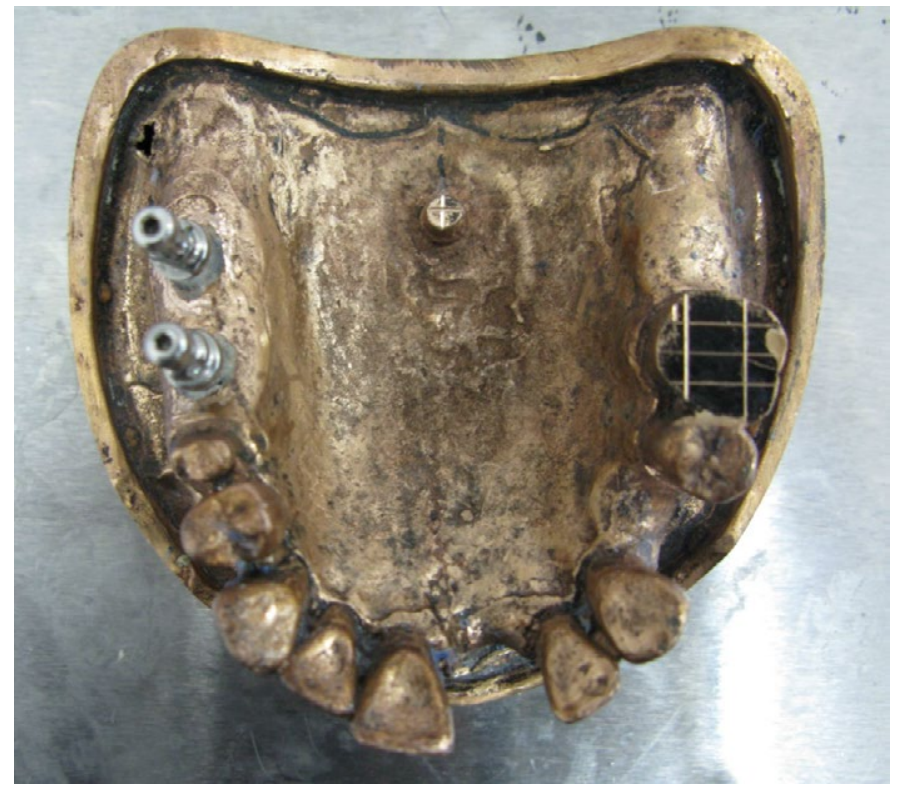

Figure 1. The metal reference model with two implants and a prepared tooth with three reference lines.
Table 1. The Absolute amount $(\mathrm{mm})$ of displacement in each group.

\begin{tabular}{|l|l|l|l|l|l|}
\hline Impression Technique & Mean $\Delta x(S D)$ & Mean $\Delta y(S D)$ & Mean $\Delta r(S D)$ & Mean $\Delta \boldsymbol{\theta}(\mathbf{S D})$ \\
\hline $\begin{array}{l}\text { Custom-Tray } \\
\text { (putty/wash) }\end{array}$ & One-step & $.185(.080)$ & $.040(.036)$ & $.196(.069)$ & $1.866(.675)$ \\
\cline { 2 - 6 } & two-step & $.237(.120)$ & $.032(.026)$ & $.240(.119)$ & $1.857(.448)$ \\
\hline $\begin{array}{l}\text { Stock-Tray } \\
\text { (putty/wash) }\end{array}$ & one- step & $.302(.196)$ & $.031(.034)$ & $.309(.190)$ & $.511(.319)$ \\
\cline { 2 - 6 } & two-step & $.148(.095)$ & $.093(.045)$ & $.184(.088)$ & $1.945(1.026)$ \\
\hline $\begin{array}{l}\text { Custom-Tray } \\
\text { (regular body) }\end{array}$ & $1.081(.230)^{*}$ & $.023(.011)^{*}$ & $1.082(.234)^{*}$ & $.534(.243)^{*}$ \\
\hline
\end{tabular}

Identical colors imply on the significant differences among test groups ( $P$ values: Red .047 ; pink and violet .003 ; blue and green $<.001$ ).

* Custom-tray regular-body differs from all other groups $(P<.001)$ in all measurements except angular displacement of Stock-one step and vertical displacement of all groups except stock-two step.

(Implantium, Dentium, Seoul, South Korea) in the holes using the fixture adaptor on the vertical rod of a surveyor (J.M. Ney Co., Bloomfield, CT). Also, three horizontal lines $(0.25,0.50$ and $0.75 \mathrm{~mm}$ in width) were cut between two vertical lines on the flat superior surface of a die according to a modification of the ISO 4823. An irreversible hydrocolloid (Alginoplast, HeraeusKulzer GmbH \& Co., Wehrheim, Germany) impression was made of the model withtwo conical transfer copings fitted to the implants to make a cast on which all custom trays (10 closed trays for regular PVS and 20 closed trays for putty/wash PVS) were fabricated. Thirty $2 \mathrm{~mm}$-thick custom trays were made with light activating polymerizing resin (Megatray, Megadenta, Radeberg, Germany). Also, twenty plastic stock-trays were used for one-step and two-step techniques. Regular and putty/wash PVS impression materials (Elite $\mathrm{HD}^{+}$, Zhermack, Italy) were the impression materials of choice for transfer procedures, and were managed according to its manufacturers' recommendations and the specification number 19 of $\mathrm{ADA}[42,43]$. Impression making procedure was performed in a controlled temperature environment $\left(23 \pm 2^{\circ} \mathrm{C}\right)$ with a relative humidity of $50 \pm 10 \%$ [14]. Impression adhesive (universal, 3M ESPE, Seefeld, Germany) was used to cover borders and interior part of all trays 15 minutes before impression making.

The specimens were assigned into five groups: one-step stock tray group, one-step custom tray group, two-step stock tray group, twostep custom tray group and regular PVS group (Table 1). In all groups, conical transfer copings (Implantium, Dentium) were secured into implants using uniform $10 \mathrm{~N} / \mathrm{cm}$ torque $[12,13]$ and the putty material was mixed with hand until the color was uniform, and all of the other materials were machine-mixed (Pentamix, 3M ESPE). Some of the wash and regular viscosity materials (in their respective groups) were injected around the transfer copings and on the lined area of model to ensure complete coverage of them. The remaining material was used to fill the trays. In two-step technique, after securing conical transfer copings, they were covered with a layer of base plate wax before taking putty impression and then after polymerization of the preliminary putty impression, the wax was removed from the impression and the light body material was added in the second step. The model was cleaned ultrasonically before impression making. Care was taken to prevent contamination of the lines before impression making. Trays were hold in place by a $5 \mathrm{~kg}$ weight while placed in $36 \pm 1^{\circ} \mathrm{C}$ water during impression setting [14]. The impressions were separated from the casts five minutes later and impressions were inspected and repeated when any inaccuracies were found such as voids or impression separation from the tray. After separating the conical copings from the model and them to the implant analogues, they were replaced in the impression. 
After boxing the impressions, they were poured with vacuummixed dental stone type IV (Herostonel Vigodent Inc., Rio de Janeiro, $\mathrm{RJ}$, Brazil) with a powder/water ratio of $30 \mathrm{~g} / 7 \mathrm{~mL}$. After 120 minutes later, the impressions were removed from the casts. All the procedure was performed bythe same operator.

All readings were conducted by one calibrated examiner randomly in order to measure the positional accuracy of the implant replicas using a coordinate measuring machine (CMM) (Mistral, DEA Brown \& Sharpe, Grugliasco, Italy) with $2.8 \mu \mathrm{m}$ accuracy for the $\mathrm{x}-, \mathrm{y}$ - axis. The distance between the implant openings in $-\mathrm{x}$ and $-\mathrm{y}$ direction and the reference point was recorded by the 0.5 - $\mathrm{mm}$-wide straight CMM probe. The flat side of the transfer copings was considered as reference for measuring the angular changes. These linear and angular measurements performed on the master model as well as working casts (Figure 2). Each cast was evaluated three times (with an average), and the distances from the reference point on the center of model were compared with the master models. Also, to determine the accuracy of surface detail reproduction, video measuring machine (VMM) (Starrett, Galileo Vision System, England) was used. A 0.5-mm-wide straight VMM probe recorded the three points in the widest part of lines. The average width was calculated by dividing the sum of width

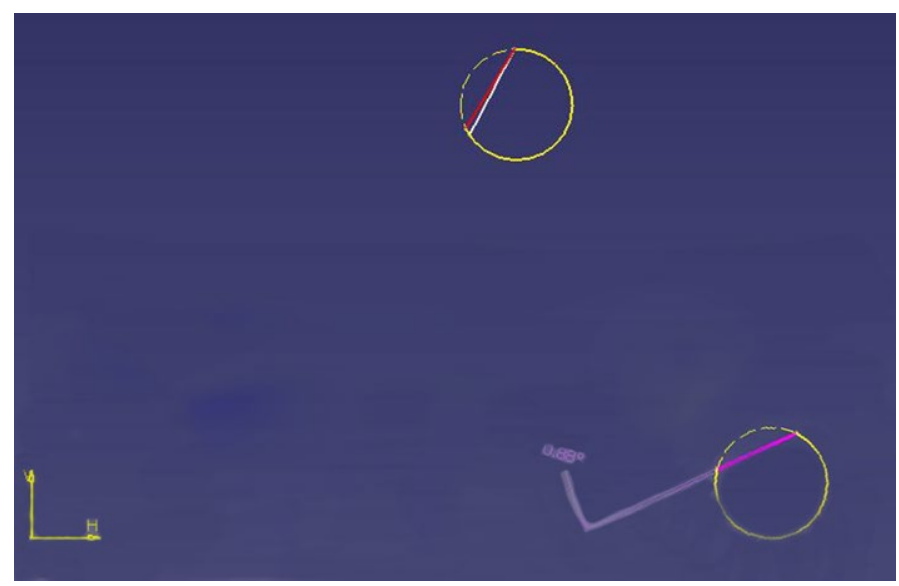

Figure 2. Schematic drawings of the measurements of implants in $\mathrm{x}$, and $\mathrm{y}$ direction and also rotational displacement.

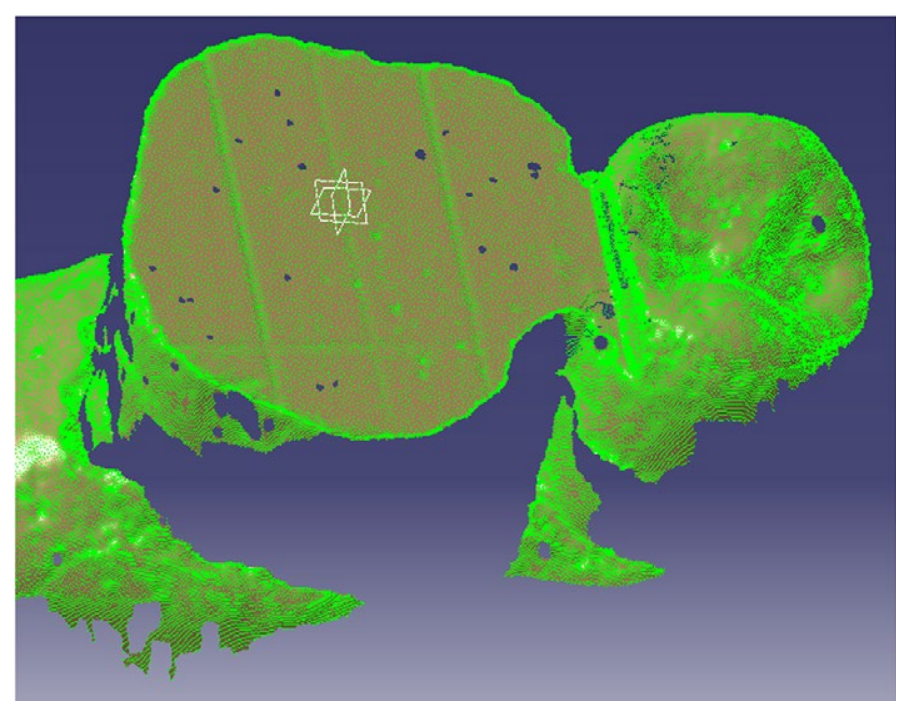

Figure 3. Schematic drawing of the width measurements of three horizontal lines with measuring machine.
Table 2. The absolute amount $(\mu \mathrm{m})$ of differences and SDs in each group.

\begin{tabular}{|l|l|l|l|l|}
\hline \multicolumn{2}{|l|}{ Impression Technique } & Narrow line & Medium line & Wide line \\
\hline \multirow{2}{*}{ Custom-Tray (putty/wash) } & One step & $12.33(6.34)$ & $12.33(9.59)$ & $19.00(13.42)$ \\
\cline { 2 - 5 } & Two step & $11.89(4.08)$ & $7.44(3.94)$ & $18.11(7.42)$ \\
\hline \multirow{2}{*}{ Stock-Tray (putty/wash) } & One step & $10.30(6.09)$ & $5.90(3.41)$ & $10.80(5.33)$ \\
\hline & Two step & $11.22(4.52)$ & $9.00(8.35)$ & $16.22(11.03)$ \\
\hline Custom-Tray (regular body) & Closed & $9.92(4.71)$ & $8.72(6.101)$ & $13.96(8.41)$ \\
\hline
\end{tabular}

No significant differences were found among all groups.

measurements by three (Figure 3 ). The data obtained from the readings were recorded and summarized in tables. All data were presented in absolute values in each direction. Their means and standard deviations were calculated and then submitted to the analysis of variance with one variable (impression technique) at a significance of $5 \%(P<.05)$., The post hoc Tukey test was used after differences among the groups were identified.

\section{Result}

The mean and standard deviation measurements of displacements in the $\mathrm{x}$ and $\mathrm{y}$ directions, angular displacement, and also surface detail reproduction of three lines are presented in Tables1 and 2. Linear displacement $(\Delta \mathrm{r})$ was calculated using the equation $\Delta \mathrm{r}^{2}=\Delta \mathrm{x}^{2}+\Delta \mathrm{y}^{2}$ which represents the two-dimensional linear displacement.

Two-step stock-tray group had less horizontal displacement compared to one-step technique with stock-tray $(P=.047)$. However, There was less vertical and angular displacement in one-step stock-tray group compared to two-step stock-tray group $(P=0.003$ and $P<0.001$ respectively) (Table1).

Two-step custom-tray group produced less vertical displacement than two-step stock-tray $(P=0.003)$. However, there was more angular displacement in one-step custom-tray group compared to one-step stock-tray group $(P<0.001)$ (Table1).

Regular-body group showed more linear and horizontal displacements compared to all other groups. On the other hand, this group had less angular displacement compared to all other groups except one-step stock-tray group and less vertical displacement in comparison to other groups except two-step stock-tray group $(P<.001)$ (Table 1).

The results also revealed that the detail reproduction, measured by VMM, had no statistically significant differencesin all groups $(P>0.05)$ (Table 2).

\section{Discussion}

In certain clinical situations, making a single accurateimpression for transferring 3-dimentional position of implants and reproducing details of prepared teeth is needed. Selection of the appropriate impression material and technique is critical to achieve a passively fitting super structure for implants [5] and also internal and marginal fitness of the cast restorations [2]. Literature shows a variety of impression techniques for impression making of implants [1,9-14] and yet no agreement has been reached upon the most accurate technique and material. Although there is a technical report about an impression technique for simultaneous impression making of implant and natural tooth by Cannistraci [3], this issue has not been the subject of any original research before.

This study evaluated different viscosities of PVS impression 
material with different techniques using stock and custom trays and conical transfer copings for implant transfer and surface detail reproduction. It has been claimed that the inaccuracy of indirect impression technique may be due to permanent deformation of a stiff impression material such as polyether [9] which does not allow complete and accurate repositioning of conical impression coping back into its respective notch in the impression. Therefore, it is possible that use of an impression material with greater elastic recovery [28-30], such as PVS, provide better results for indirect impression technique. Furthermore, PVS is capable of precise reproduction of details [28-30] which is necessary for recording details of teeth. Most of the literature about the putty/wash impression technique belongs to tooth rather than implant studies. Closed impression trays may be more susceptible to flexion and distortion which could affect both position and dimensions of the teeth [38]. However, for implant-level impression technique only recording the implant head position is of great importance. Also, it should be mentioned that not all implant systems provide conical transfer coping which should be considered in selection of impression technique. Before impression making, tray adhesive was used to ensure the bond between tray and impression material during tray removal. Besides, use of tray adhesive would change the direction of material shrinkage toward the tray walls instead of toward the center of the impression [17].

In comparison between one-step groups, there was less angular displacement using the stock tray. Since in one-step technique there would be no guarantee for a uniform space for the wash material, use of a more flexible tray such as a plastic stock tray probably would provide more space for this material. Furthermore, when a stock tray is used with a high-viscosity impression material (putty), there is less concern about the shortcomings of such tray because a putty customized tray would result [18]. Therefore, since stock trays are readily available and easy to use, they could be recommended to be used with one-step technique.

In comparison between two-step groups, however, using custom tray delivered less vertical displacement as compared to stock tray. This could be the result of tray type, because rigid acrylic custom trays are more accurate than plastic stock trays for making impression which is due to their rigidity and availability for providing uniform space for impression materials. Flexibility of plastic stock trays and uneven thickness of impression material in them could be responsible for distortion of impression [38-40]. A high-viscosity impression material (putty) has the potential to compensate for the extra space inside a stock tray [43] and therefore acting as a custom tray for the wash material [18]. However, the stiffness of putty material itself could result in distortion of the plastic stock tray when the tray is not sufficiently rigid to resist the pressure during seating [19]. Therefore, custom trays might be more accurate and also economical, because less impression material would be needed. It has been reported that the amount of impression material needed to make an impression with a stock tray is twice as much as with the custom tray [33]. Nevertheless, according to some studies a rigid metal stock tray is probably preferred to plastic stock tray for implant or tooth impressions with a high-viscosity PVS $[2,20]$. Regarding the results of this study, depending on the impression technique both stock tray and custom tray were acceptable if managed correctly.

Also, in comparison between one and two-step techniques using stock tray, there was less horizontal displacement in two-step technique.This result supports the findings of Nissan et al. [21,24] study that showed that providing $2 \mathrm{~mm}$ space for the wash material in two-step technique, results in more accurate impressions rather than one-step technique or using a polyethylene spacer. This is because of uncontrolled bulk of wash material in the two latter situations [18]. In a two-step technique the wash material is used after the putty has polymerized and undergone contraction. Therefore, only minimal dimensional changes would occur due to further contraction of the wash material $[21,22]$. When the wash bulk is not controlled, it may allow differential contractions which finally result in uneven dimensional changes [23]. By reducing the bulk of the polymerizing material at each stage, the ultimate contraction will also be reduced, and the accuracy of the impression can be increased [25]. Nissan et al. $[21,24]$ also reported that dimensional changes during setting were in proportion to the wash material thickness. They also showed that in order to make the most accurate stone dies, 1 to $2 \mathrm{~mm}$ wash material is needed in a putty/wash technique $[21,24]$.

However, there were fewer displacements in vertical and angular directions for one-step technique using stock trays. This finding could be explained by this fact that there is a probability of wash material being pushed away and the stiffer material (putty) engaging the transfer copings in one-step technique, it could result in a more stable repositioning of copings into the impression that prevents their excessive rotation in the impression. Also, this finding is in agreement with results of Wenz et al. [37] who reported that the one-step technique was more accurate than the two-step technique using PVS and custom trays. The advantage of one-step technique is its simplicity and also saving time and impression material. Knowing that the closer the $P$ value gets to 0 , the greaterthe results become statistically significant, since the $P$ value for horizontal displacement was greater than for vertical and angular displacements, in general it could be concluded that one-step technique yielded more accurate results than two-step technique using stock tray.

The findings of the present study also indicated more displacements for regular viscosity PVS using custom tray in comparison to putty/ wash groups. This may be because of greater stiffness and filler content of putty material in comparison to regular viscosity material, which consequently means more polymerization shrinkage of regular viscosity PVS. Although using single viscosity (mono-phase) PVS for impression technique is very easy, it has been reported to be less accurate than two-phase PVS in terms of creating more surface voids, which is due to its relatively high viscosity and reduced flow [35].

The results of this study also showed no statistical differences for surface detail reproduction among all groups. In general, the lower is the viscosity of impression material; the better is the reproduction of fine details. Often, in putty/wash technique (especially one-step), critical areas of the prepared teeth, such as cervical margins, are recorded in putty material whichis claimed to be capable of recording detail with at least $75 \mu \mathrm{m}$ width $[26,27]$. While in this study VMM with $0.3 \mu \mathrm{m}$ accuracy was used to measure width of lines on the definitive casts, some studiesused the criteria of ADA specification no.19, which is continuous replication of at least 2 out of the 3 horizontal lines under $\times 10$ magnification [31] or using a measuring microscope with an accuracy of $0.001 \mathrm{~mm}$ [32]. In some groups the SDs had the same magnitudes as the mean values. Some factors such as errors in impression procedure, contraction of the impression material or investment expansion may be responsible for this result. Another reason could be the fact that the VMM is more accurate than the wire cutting machine which was used for inscribing the lines on the model. 
Evaluating the surface detail reproduction of PVS in only dry condition was one of the limitations of this study. Also, further research is needed to investigate and compare the ability of gypsum die materials for replicating fine details. Also, the effect of different number and angulation of implants in presence of prepared teeth and different impression materials and techniques must be investigated.

\section{Conclusion}

Within the limitations of this in vitro study, it could be concluded that the both stock and custom trays were acceptable. One-step technique showed better results than two-step technique in combination with stock trays. The putty/wash PVS either in one or two-step technique, was more accurate than using regular viscosity PVS. Also, the viscosity of impression material (PVS) did not affect the surface detail reproduction.

\section{Acknowledgment}

This project was funded by a grant (No. 86-03-69-6033) from the Tehran University of Medical Sciences. The authors also express special thanks to DorsanTeb Pars Company for their generous support.

\section{References}

1. Kim S Nicholls JI, Han CH, Lee KW (2006) Displacement of implant components from impressions to definitive casts. Int J Oral Maxillofac Implants 21: 747-755. [Crossref]

2. Cho GC Chee WW (2004) Distortion of disposable plastic stock trays when used with putty vinyl polysiloxane impression materials. J Prosthet Dent 92: 354-358. [Crossref]

3. Chee WW Alexander ML (1998) Impression technique for arches requiring both implant and natural tooth restorations. J Prosthodont 7: 45-48. [Crossref]

4. Jo SH Kim KI, Seo JM, Song KY, Park JM, et al. (2010) Effect of impression coping and implant angulation on the accuracy of implant impressions: an in vitro study. $J A d v$ Prosthodont 2: 128-133. [Crossref]

5. Wee AG Aquilino SA, Schneider RL (1999) Strategies to achieve fit in implant prosthodontics: a review of the literature. Int J Prosthodont 12: 167-178. [Crossref]

6. Sahin S, Cehrli MC (2001) The significance of passive framework fit in implant prosthodentics: current status. Implant Dent 10: 85-92. [Crossref]

7. Balshi TJ (1996) An analysis and management of fractured implants: a clinical report. Int J Oral Maxillofac Implants 11: 660-666. [Crossref]

8. Eckert SE Meraw SJ, Cal E, Ow RK (2000) Analysis of incidence and associated factors with fractured implants: a retrospective study. Int J Oral Maxillofac Implants 15: 662-667. [Crossref]

9. Carr AB (1991) Comparison of impression techniques for a five-implant mandibular model. Int J Oral Maxillofac Implants 6: 448-455. [Crossref]

10. Cabral LM Guedes CG (2007) Comparative analysis of 4 impression techniques for implants. Implant Dent 16: 187-194. [Crossref]

11. Vigolo P Fonzi F, Majzoub Z, Cordioli G (2004) An evaluation of impression techniques for multiple internal connection implant prostheses. J Prosthet Dent 92 : 470-476. [Crossref]

12. Vigolo P Majzoub Z, Cordioli G (2000) In vitro comparison of master cast accuracy for single-tooth implant replacement. J Prosthet Dent 83: 562-566. [Crossref]

13. Inturregui JA Aquilino SA, Ryther JS, Lund PS (1993) Evaluation of three impression techniques for osseointegrated oral implants. J Prosthet Dent 69: 503-509. [Crossref]

14. Rashidan N Alikhasi M, Samadizadeh S, Beyabanaki E, Kharazifard MJ (2012) Accuracy of implant impressions with different impression coping types and shapes. Clin Implant Dent Relat Res 14: 218-225. [Crossref]

15. Gordon GE Johnson GH, Drennon DG (1990) The effect of tray selection on the accuracy of elastomeric impression materials. J Prosthet Dent 63: 12-15. [Crossref]

16. Millstein P Maya A, Segura C (1998) Determining the accuracy of stock and custom tray impression/casts. J Oral Rehabil 25: 645-648. [Crossref]
17. Johnson GH, Craig RG (1985) Accuracy of four types of rubber impression materials compared with time of pour and a repeat pour of models. J Prosthet Dent 53: 484-490. [Crossref]

18. Donovan TE Chee WW (2004) A review of contemporary impression materials and techniques. Dent Clin North Am 48: vi-vii, 445-70. [Crossref]

19. Masri R, Driscoll CF, Burkhardt J, Von Fraunhofer A, Romberg E (2002) Pressure generated on a simulated oral analog by impression materials in custom trays of different designs. J Prosthodont 11: 155-160. [Crossref]

20. Del'acqua MA de Avila ÉD, Amaral ÂL, Pinelli LA, de Assis Mollo F Jr (2012) Comparison of the accuracy of plastic and metal stock trays for implant impressions. Int J Oral Maxillofac Implants 27: 544-550. [Crossref]

21. Nissan J Laufer BZ, Brosh T, Assif D (2000) Accuracy of three polyvinyl siloxane putty-wash impression techniques. J Prosthet Dent 83: 161-165. [Crossref]

22. Eames WB, Sieweke JC, Wallace SW, Rogers LB (1979) Elastomeric impression materials: effect of bulk on accuracy. J Prosthet Dent 41: 304-307. [Crossref]

23. Lewinstein I (1993) The ratio between vertical and horizontal changes of impressions. J Oral Rehabil 20: 107-114. [Crossref]

24. Nissan J Gross M, Shifman A, Assif D (2002) Effect of wash bulk on the accuracy of polyvinyl siloxane putty-wash impressions. J Oral Rehabil 29: 357-361. [Crossref]

25. Schoenrock GA (1989) The laminar impression technique. J Prosthet Dent 62: 392-395. [Crossref]

26. Idris B Houston F, Claffey N (1995) Comparison of the dimensional accuracy of one- and two-step techniques with the use of putty/wash addition silicone impression materials. J Prosthet Dent 74: 535-541. [Crossref]

27. Chee WW, Donovan TE (1989) Fine detail reproduction of very high viscosity poly(vinyl siloxane) impression materials. Int J Prosthodont 2: 368-370. [Crossref]

28. Reisbick MH, Matyas J (1975) The accuracy of highly filled elastomeric impression materials. J Prosthet Dent 33: 67-72.

29. Lacy AM, Fukui H, Bellman T, Jendresen MD (1981) Time-dependent accuracy of elastomer impression materials. Part II: Polyether, polysulfides, and polyvinylsiloxane. $J$ Prosthet Dent 45: 329-333. [Crossref]

30. American Dental Association (1990) Vinyl polysiloxane impression materials: a status report. Council of Dental Materials, Instruments and Equipment. J Am Dent Assoc 120:595-596-598-600. [Crossref]

31. Gerrow JD Price RB (1998) Comparison of the surface detail reproduction of flexible die material systems. J Prosthet Dent 80: 485-489. [Crossref]

32. Petrie CS Walker MP, O'mahony AM, Spencer P (2003) Dimensional accuracy and surface detail reproduction of two hydrophilic vinyl polysiloxane impression materials tested under dry, moist, and wet conditions. J Prosthet Dent 90: 365-372. [Crossref]

33. Phillips RW (1983) Science of dental materials. WB Saunders, Philladelphia, 149-150.

34. Caputi S Varvara G (2008) Dimensional accuracy of resultant casts made by a monophase, one-step and two-step, and a novel two-step putty/light-body impression technique: an in vitro study. J Prosthet Dent 99: 274-281. [Crossref]

35. Millar BJ Dunne SM, Robinson PB (1998) In vitro study of the number of surface defects in monophase and two-phase addition silicone impressions. J Prosthet Dent 80: 32-35. [Crossref]

36. Hung SH Purk JH, Tira DE, Eick JD (1992) Accuracy of one-step versus two-step putty wash addition silicone impression technique. $J$ Prosthet Dent 67: 583-589. [Crossref]

37. Wenz HJ Hertrampf K (2008) Accuracy of impressions and casts using different implant impression techniques in a multi-implant system with an internal hex connection. Int $J$ Oral Maxillofac Implants 23: 39-47. [Crossref]

38. Burns J Palmer R, Howe L, Wilson R (2003) Accuracy of open tray implant impressions: an in vitro comparison of stock versus custom trays. J Prosthet Dent 89: 250-255. [Crossref]

39. Wassell RW Ibbetson RJ (1991) The accuracy of polyvinyl siloxane impressions made with standard and reinforced stock trays. J Prosthet Dent 65: 748-757. [Crossref]

40. Rueda LJ Sy-Muñoz JT, Naylor WP, Goodacre CJ, Swartz ML (1996) The effect of using custom or stock trays on the accuracy of gypsum casts. Int J Prosthodont 9 : 367-373. [Crossref]

41. Thongthammachat S Moore BK, Barco MT 2nd, Hovijitra S, Brown DT, et al. (2002) Dimensional accuracy of dental casts: influence of tray material, impression material, and time. J Prosthodont 11: 98-108. [Crossref] 
Beyabanaki E (2015) Accuracy of implant transfer using closed tray technique with different viscosities of polyvinyl siloxane

42. [No authors listed] (1977) Revised American Dental Association Specification no. 19 for Non-aqueous, Elastomeric Dental Impression Materials. J Am Dent Assoc 94: 733741. [Crossref]
43. Anusavice KJ (2003) Phillips' Science of Dental Materials. Philadelphia, WB, Saunders, 221.

Copyright: (C2015 Beyabanaki E. This is an open-access article distributed under the terms of the Creative Commons Attribution License, which permits unrestricted use, distribution, and reproduction in any medium, provided the original author and source are credited. 